Article

\title{
Experience in the Use of Social Software to Support Student Learning in University Courses of Science and Engineering Degrees
}

\author{
Ana María Díez-Pascual ${ }^{1, * \mathbb{C}}$, Pilar García-Díaz ${ }^{2} \mathbb{D}$ and Rafael Peña-Capilla ${ }^{2}$ \\ 1 Department of Analytical Chemistry, Physical Chemistry and Chemical Engineering, Faculty of Sciences, \\ Alcalá University, 28871 Madrid, Spain \\ 2 Department of Signal Theory and Communications, Polytechnic High School, Alcalá University, \\ 28871 Madrid, Spain; pilar.garcia@uah.es (P.G.-D.); rafael.pena@uah.es (R.P.-C.) \\ * Correspondence: am.diez@uah.es; Tel.: +34-918-856-430
}

Received: 31 October 2018; Accepted: 23 December 2018; Published: 28 December 2018

\begin{abstract}
A wiki is an easy-to-use online tool for teachers and students, as it is a collaborative website that provides the opportunity to develop and modify its content to every member in an interactive and fast way. This paper comparatively describes experiences in the implementation of wikis as voluntary activities in first-year courses in a degree in Chemistry and third-year courses in a degree in Telecommunication System Engineering. The main goal of using the wikis was to achieve collaboration among students to generate knowledge. The developed methodology was applied to the resolution of exercises, problems, and test questions, as well as to the elaboration of class notes and a bilingual glossary. The approach turned the students into active learners, increasing their interest in the course contents, promoting knowledge exchange among students and encouraging the self-management of their learning process. The role of the teacher was to provide feedback to the students in order to ensure the accuracy of the contents. Four different patterns were distinguished among the students according to their participation level in the wiki. The students who were most committed to the courses were also the most involved in the wikis, and the combination resulted in the students' success. The results obtained for the degree in Chemistry were better than those of the degree in Telecommunication System Engineering, which was ascribed to the increased connection among the first-year students. The didactic strategy was very positive, although the percentage of participation in the wikis was somewhat low, in particular for the third-year students, who were more independent and self-organized. Initially, the number of wiki visits increased suddenly, and then moved to a long period of lower activity in the degree of Chemistry and lethargy in the degree of Telecommunication System Engineering. Therefore, it is desirable to introduce modifications in the approach, such as flexible and consensual planning with the students in order to ensure their full engagement.
\end{abstract}

Keywords: wiki; methodology; collaborative learning; social software; feedback; student engagement

\section{Introduction}

A wiki is a collaborative website that allows users to create, add to, modify, or delete its content and structure in an interactive, simple, and quick way [1]; these features make it a highly suitable platform for collaborative writing, where members work in partnership to develop content on a particular topic [2]. Both wikis and blogs are social software tools that promote collaborative learning, despite the key differences between them regarding the notification of new content, editing format, and structure. Initially, a blog was a personal website created by an individual to share information 
on a single subject. Blogs usually had a single author/editor, who added content they considered interesting, and readers then commented after its publication. The author controlled the blog space and decided which comments would appear in the blog. Currently, there are "multi-author blogs" (MABs), in which posts are developed, written, and professionally edited by a large number of authors; hence, they have a collaborative character. Conversely, in a wiki, every member can edit the contents and take part in the discussion. Mattison [3] stated that "a wiki can be a blog, but a blog does not have to be a wiki". The use of wikis is frequently compared with blogging. Blogs are structured chronologically, whilst the structure of wikis is based on hierarchical subject divisions by means of new page formation and internal and external hyperlinking. These characteristics make wikis greatly appropriate for educational use. Wikis are more flexible, while blogs are more ordered. Most of the wikis feature a search option, while many blogs do not. Once a blog addition is posted, it seldom can be edited. However, user communities are found at both blog and wiki sites.

In 2004, Web 2.0 technologies introduced a new generation of Web-based communities. Wikis were one of the most successful Web 2.0 services; they acted as tools that facilitated creativity, collaboration, and offered users the possibility of sharing content and other resources, regardless of their diversity or geographical location. It is essential to name Wikipedia, the free encyclopedia and collective construction, as the icon of what represents the possibilities of this computer technology on the Internet. Wikipedia is currently the sixth most visited website in all of cyberspace, above such renowned sites as Blogger, MSN, Twitter, Myspace, Microsoft, Amazon, eBay, and Apple, among others.

There is another Web concept based on the term hypertext, which can be defined as "a non-linear and sequential organization of information, where it is the user who decides the path to follow and the relationships to be established between the different information blocks that are offered to him, being able in some of them even to check new relationships not foreseen by the designer of the program" [4]. With the development of collaborative tools, the reader stops being just a reader (passive) and becomes a reader-author (active). Thus, the concept of online collaboration or altruism emerged on the Internet. A person deposits their knowledge altruistically and free so that others can use this content, without the need to give anything in return. With the knowledge of each other, the network is built.

In a traditional wiki, there are three presentations per page, which include:

- A source code that users can edit. It is usually a plain text, and is only visible to the user when the "edit" operation is active;

- A template, which is usually created by the wiki administrator and is not modifiable by the users, and defines the common elements of all the pages and their position;

- The HTML code, which is compiled in real time by the server from the source code each time the page executes the compilation operation.

Wikis usually have a vertical menu on the left that includes the elements or tools that are oriented to facilitate navigation (such as links to the wiki itself, recent changes, and support tools to upload files, among others). Besides, there are resources to edit and add comments by the users in the discussion section. In addition to the maintenance tasks of the software, wikis require a series of maintenance works to be performed by the users themselves, including style corrections, spelling, grammar, corrections of links, images, etc. Further, there are other functions such as the "Revision History", where old versions of the page are displayed. The user editor can view and restore an earlier version of the content from this page. The method and philosophy that is used for both creation and correction is peer review, which is defined as the "method used to improve the quality of written work, leaving the work open to scrutiny and, frequently, annotation or editing by a number of authors equal in rank to the author" [5]. The main basis is that different people will see diverse errors, which increases the probability of their discovery and the possibility of amending them. This tradition has been known for a long time in the academic community, and enables improving the work quality. 
The wikis applied to teaching let the students show their accomplishments during the learning process [6]. Additionally, they are beneficial to the teaching-learning process, since they enhance essential functions such as:

- Student motivation: University students are fully integrated in the use of new technologies. Internet applications exert a high level of influence on young people. By approximating the teaching objectives to the applications that students are interested in, a certain degree of persuasion is exerted to increase motivation through developing activities that will promote their learning [7]. Traditional teaching activities, while being valid for understanding content, are less likely to be attractive among students. In general, the use of innovative tools increases the probabilities of success in the learning process facilitated by the mere curiosity of the students; instilling curiosity encourages their desire to carry out activities related to the course [8].

- Student support in inquiry for learning: The correlation between the interest and need felt by the student and the achievements attained after participating in a certain course has been demonstrated. When the teacher presents a topic in a way that captures the interest of the students, getting them to endorse the need to know, teaching success is guaranteed [9]. The need of the student will be satisfied from the material provided by the teacher, as well as from new material compiled independently. The wikis serve as a space for collecting knowledge generated collaboratively among students, allowing immediate dissemination between teachers and students, which reinforces the learning process [10].

- Evaluation tool: The teacher can evaluate the learning process as well as analyze the evolution and progress of the group of students during the course. This refers to the term "continuous formative assessment" [11]. By using the discussion area in the wiki application, the teacher can perform the tasks of correcting, guiding, proposing new lines of work, and recommending readings or specific bibliographic references for certain content. The objective of these review activities is to prevent students from making mistakes that could discourage them in their progress and knowledge development, while allowing them to explore and investigate autonomously. It should be noted that the aforementioned tasks are shared with the students, who are given some control in the management and direction of the course.

- Direct teacher-student communication line: The wikis constitute a way through which the students receive feedback [12], allowing their formative evaluation and self-evaluation. The teacher is present at all times, but acts as a supervisor rather than the provider of information, and does not write the contents directly. The wikis offer the possibility for all of the participants to interact without having to coexist in time and place, facilitating collaborative work [7] and consequently the development of quality content.

- Self-control and self-regulated learning: Both are connected to the transfer of power to the student. It is very important for the students to feel responsible for their own learning, in a way that they can acquire the skills established in the teaching guide. The students will find it difficult at the beginning, but progressively they will learn to direct themselves. Encouragement of the autonomous or "self-learning" is a powerful tool for the academic, personal, and professional development of the individuals.

The websites that are more frequently used for wiki development in the education field are: PBworks, Wetpaint, Wikia, Google Sites, and Wikispaces. All of them utilize free web services and a remote transparent server. Wikispaces is a wiki hosting service based in San Francisco (California, USA) that was launched by Tangient LLC in March 2005 and then bought by Wikispaces TSL Education in March 2014 (Figure 1); this service was used for the design of the wikis described herein, though it is possible to carry out the same activities using any other wiki service that is currently available. 


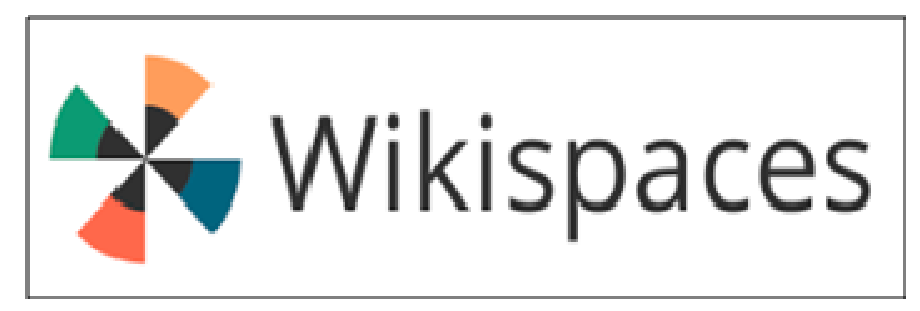

Figure 1. Wikispaces logotype (taken from the web www.wikispaces.com).

\section{Educational Learning Theories}

Although the research community had not yet agreed on a classification for the educational learning theories, these tend to fall into one of the following perspectives or paradigms [13]: behaviorism, cognitivism, constructivism, humanism, and collaborative. Behaviorism is based on the principle of "stimulus-response". It considers that all behaviors can be explained by external factors without the need to take into account internal mental states or consciousness. This classic behavirist model assumes that the learner is passive and the aim of teaching is to efficiently transfer knowledge from the expert to the learner. In contrast to behaviorism, cognitivism does not involve an external exhibition of learning; it is more focused on the internal processes and connections that take place during learning, opening the "black box" of the human mind [14]. It is essential to determine how processes such as knowing, thinking, memorizing, and problem-solving occur. Learners are not "automatic animals" that simply react to environmental stimuli; they are rational beings whose actions are the outcome of thinking. In this theory, students learn most effectively through reading text and lecture instruction.

The basic idea in the humanism theory is that learning is a personal act to realize one's full potential. Learners can be viewed as individuals with affective and cognitive needs, and special emphasis is placed on the freedom, dignity, and potential of humans. Learning is student-centered and individual; however, it is assisted by teachers, with the aim of developing self-actualized people in a cooperative, supportive environment.

The aforementioned characteristics of the wiki technology suit the other two theories of learning: constructivist and collaborative. Both differ from the classic behaviorist model, since they encourage effective learning by promoting: (1) active learning and knowledge build-up, (2) cooperation and teamwork, and (3) problem solving. A key principle of the constructivist theory is that learners should actively construct their own learning. Constructivism requires learner-centered teaching; educational materials that aid the students to learn concepts and experiences for themselves have to be provided rather than a simple passive tuition [15]. The foremost characteristics of this theory can be summarized as follows:

- All knowledge is built via a reflective abstraction process;

- Cognitive structures within individuals aid the learning process;

- The cognitive structures are in a process of continuous development;

- Methods of learning and teaching must agree.

To boost knowledge construction, students are encouraged to explore new possibilities, formulate alternative solutions, collaborate with other students, test ideas and hypotheses, revise their thinking, and finally expose the best solution found.

Cooperative learning can be placed within the social constructivist paradigm. Students work in teams on projects or problems with both personal and team accountability for conceptual understanding. This theory considers that learning occurs as individuals work out, corroborate, and improve their mental models via discussion and information sharing with others [15]. In contrast to constructivism, the main assumptions of collaborative learning are:

- Knowledge is created as it is shared; 
- Learners have previous knowledge that can be added to the discussion;

- Participation is decisive for learning;

- Learners will participate if optimal conditions are provided.

Further, collaborative learning provides numerous benefits, including [16]:

- Improved student involvement with the subject matter;

- Better critical thinking and problem-solving skills amongst students, and

- Enhanced student learning and achievement.

Wikis can be applied to make this type of active learning possible, in which computers are used to promote peer interaction and group work. The asynchronous nature of such collaboration can be visualized as promoting cooperation rather than competition amongst students.

\section{Purpose, Research Questions, and Methodology}

\subsection{Aims of the Study and Research Design}

The general purpose of this article is to comparatively analyze the experiences of using wikis to carry out activities belonging to the courses "Basic Lab Operations" and "Digital Communications". The first is a practical compulsory course of nine ECTS (European Credit Transfer System) credits of the first year of a degree in Chemistry with a cohort size of 110 students, while the second is a compulsory course of six ECTS credits of the third year of a degree in Telecommunication System Engineering with 80 students. The activities were regarded as voluntary tasks, since their compulsory nature would have turned them into work, while learning in higher education should not be forced. Their voluntary nature promotes the students' autonomy and management of the learning process, which is crucial from an educational perspective. Therefore, the activities were not included within the assessment criteria in the course guide, although they had a positive effect on the final mark of the students.

The specific aims of the current study are the following:

- Assess the potential of wikis within the framework of higher education;

- Compare teaching experiences in the use of wikis within different courses of the experimental science and engineering fields;

- Promote both autonomous and collaborative work among students, making them responsible for coordinating and distributing their own tasks as well as organizing their time.

- Increase the motivation of the students for learning the course contents, which will result in a better academic performance;

- Encourage students to practice with a wider collection of exercises, problems, and practical cases than those worked in class, given that the time in class is limited and insufficient for learning all the subject content;

- Initiate the students in the search of bibliographic information; learn and update knowledge;

- Implement the use of novel social technologies within an educational context;

- Boost students' capacity for discussion, critical logic, choice, synthesis, and making decisions;

- Facilitate a platform to promote active knowledge sharing and information exchange among students. Encourage the students to share notes and course material. Knowledge sharing is critical to develop new knowledge, and enhances both individual and collective learning processes.

Taking into account the well-known relation between the wiki characteristics (collaborative work and knowledge development) and the learning models being currently promoted in higher education, the following questions were raised. (1) Can wikis be used to support student learning and engagement, that is, to help the active participation of the students with the subject matter? (2) Are wikis suitable to build knowledge repositories, in other words, to create meaningful course content? (3) Can wikis expand the students' skills by building content that supplements and extends the material delivered 
in class? Since wikis have no time or spatial limitation, could they be applied to accomplish more complex and further-reaching projects than those performed in class? (4) Could wikis enable effective knowledge sharing in higher education?

\subsection{Research Methodology}

The research methodology that was selected was action research, since it is a cyclic process of reflective practice that is especially appropriate for an educational context [17]. It is a methodology based on enhancing direct practice; in other words, it is a process in which teachers investigate teaching and learning to improve students' learning and teacher effectiveness. This methodology comprises five sequential stages: problem identification, plan of action and implementation, data collection, analysis and interpretation of data, and plan for future action [18].

Following the above-mentioned steps, firstly, a suitable wiki was developed within the Wikispaces environment in each of the subjects, which was freely available and easy to manage. Subsequently, the teachers explained to the students the aims of the activities that they had to complete with the wiki and their dynamics. Once the wiki was implemented and the students became members of the wiki, they voluntarily participated in the different proposed activities. The teacher periodically provided "feedback" through the wiki in order to improve the content as the course progressed, which included slides that encouraged students to think about issues on the wiki and guided them to further reading sources and websites. Students' participation was monitored via the "edition history" option of the wiki. Data were collected from a first-year course in Chemistry and a third year course in Telecommunication System Engineering. Reflection and analysis on wiki activities and the degree of student engagement was explored in successive seminar discussions. Additionally, the activities carried out in the wiki were shared in a final seminar at the end of the course, where the students reported their personal experience, the challenges that were encountered, and the conclusions that were drawn. They were also given self-assessment and co-assessment rubrics to evaluate their work and level of engagement, as well as anonymous questionnaires to get a better insight on the students' attitudes toward the wiki, as well as their familiarity and usage of social networking tools. Finally, the teachers reflected on the results and proposed future actions.

\section{Design and Implementation of the Wikis}

\subsection{Degree in Chemistry}

The course "Basic Lab Operations" includes a specific laboratory named "Introduction to the Experimentation in Analytical Chemistry". It consists of practical lessons where the students develop experiments in order to apply the basic concepts that were learned during the theoretical classes. Since the usual number of students in this course exceeds 100, they were divided into small groups of about 20 students each, and the different practices were carried out on a rotating basis, so that at the end of the course, all of the groups worked on the same content.

The aim of this part of the course was to initiate the students in the methodology of the analytical process and make them capable of developing scientific criteria for the evaluation of analytical results. Teamwork and knowledge of the instruments and equipment that is frequently used in analytical labs are among the specific competences that the students had to attain. To reach such competences, it is essential to get used to the specific terminology of the area; hence, it is important to carry out activities in which they use such terms. An appropriate environment for such development is a wiki, where the students can edit and revise the teamwork, which boosts both their autonomous learning and collaborative work [19]. These types of activities allow carrying out tasks that could not be performed during the lessons due to the lack of time and their practical character.

Before starting the activity, the teacher imparted a seminar in order to explain the ways of using the wiki within the Wikispaces environment to the students. Thus, all of them understood the use of the application as well as the purpose and dynamics of the activity. Examples of adequate and 
inadequate uses in the context of the course were also incorporated in the presentation. There were two distinct roles regarding the visibility of the functions of the application: organizer and member. The teacher behaved as the organizer, creator, designer, and administrator of the wiki, and was able to monitor its evolution, while the students acted as members of the wiki, with permission to edit content (authorization to write, delete, modify the format, attach objects, or include equations) and access the discussion area or comments in all of the pages of the wiki. Figure 2 is an informative announcement by Wikispaces about the possibilities of the application to distribute activities and projects among groups of students as well as visualize the activity in the wiki.

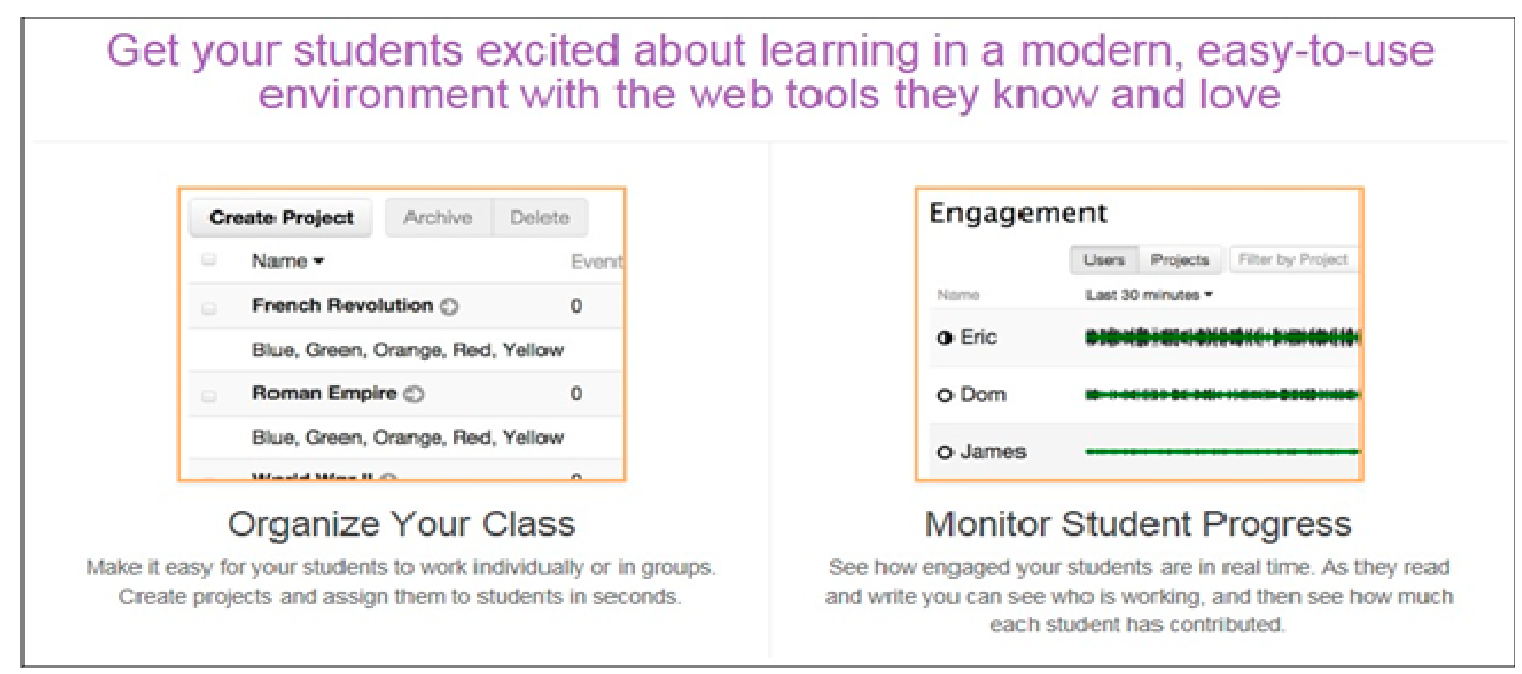

Figure 2. Activity tracking functions in a wiki (taken from the website www.wikispaces.com).

To access the wiki with any of the two profiles described, it is essential to register in Wikispaces as a user. For such purposes, a personal account linked to an email address with a username and password should be created. It is recommended that the username maintains the format "firstname.lastname" in order for all of the active members of the wiki to identify each other easily. Examples of user names appear on the right of Figure 2. The names do not match the "firstname.lastname" format because some of the alphabetic characters of the figure have been deliberately erased in order to guarantee students' anonymity. Figure 2 also shows the functionality of creating projects and composing work teams by distributing the members of the wiki among the groups. In this way, specific tasks can be assigned to certain students, and the work of each group can be visible or not to the rest of the users.

Once the students registered on Wikispaces, they had to accept an online invitation from the teacher to become members of the wiki. This invitation was carried out individually and privately through the email address of each student, though it was also possible to perform the invitation collectively, enabling a temporary login link (joincode) so that anyone who accessed through that link was admitted as a member of the wiki as long as they were previously registered in Wikispaces. Once the link period expired, admission was not possible, although a new link could be created in order to increase the number of participants in the activity.

Figure 3 shows the initial page that each student found when entering the wiki, which was named "glosarioterminosanaliticos". It comprises two sections: contents and discussion, or comments areas. In the first one, the teacher presented the activities to be carried out. In the second, all the members could insert comments related to the activities. It was a zone for collaborative discussion, both among students and between the students and the teacher. Within this environment, the teacher could suggest ideas and comments to improve the development of the activities. 


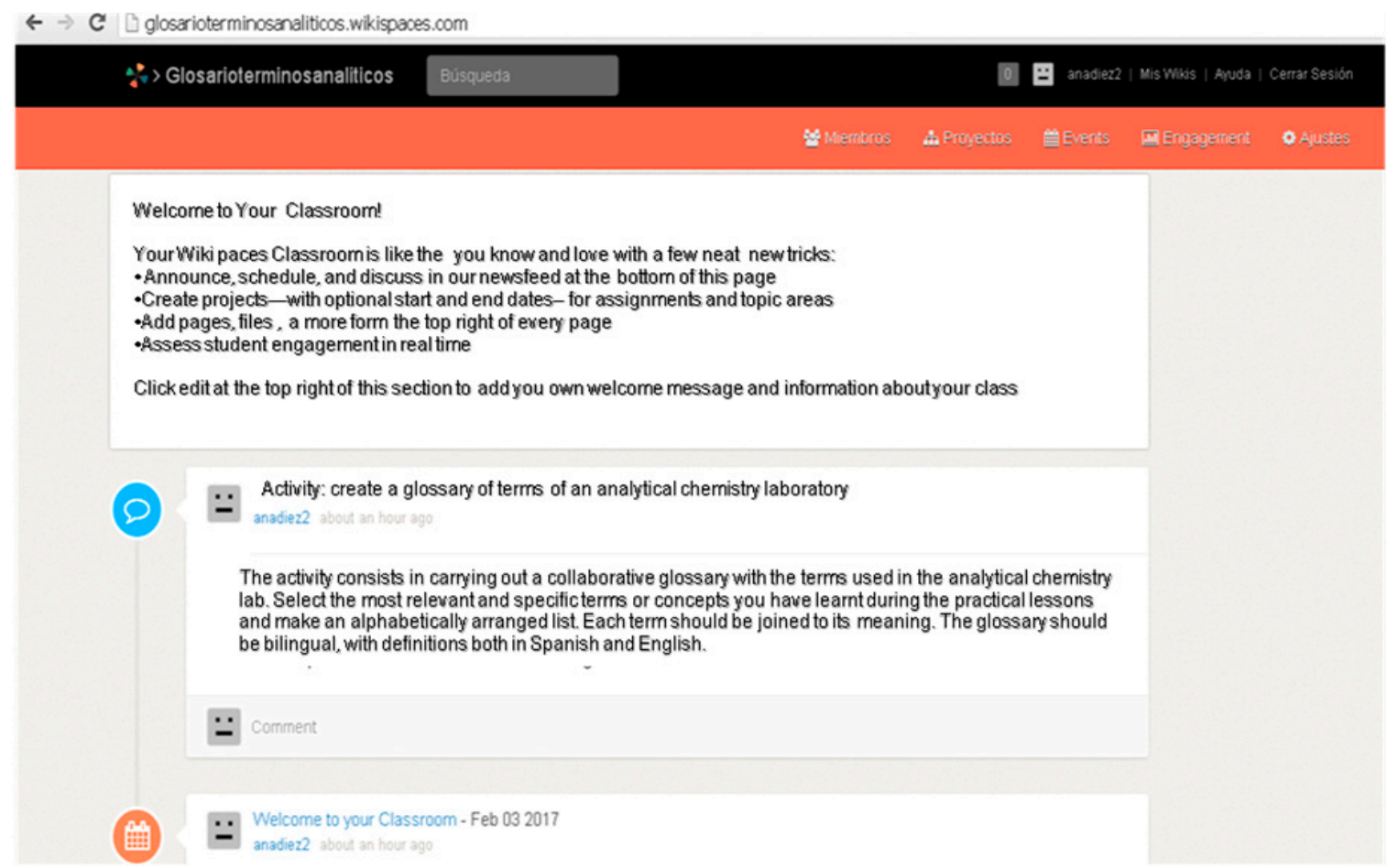

Figure 3. Initial page of the wiki "glosarioterminosanaliticos".

It is important to mention that each content modification in a wiki is recorded. This edition history of the pages is visible to all users, enabling them to check the authorship of the edition, as well as the date and time that the changes were made. This functionality is very versatile for the maintenance of the wiki, since in case inconsistencies in the contents are detected, the pages can be restored to previous valid versions.

The first activity focused on the elaboration of a collaborative glossary among all the students. They had to select the most relevant and specific terms or concepts that they had learned during the practical lessons and make an alphabetically arranged list. Each term should be associated with its meaning, similarly to Wikipedia. The glossary ought to be bilingual, both in Spanish and English. Prior to performing the activity, they should check the literature [20]. The teacher would provide "feedback" through the wiki, in a way that the students would improve the content as the course progressed.

The first task consisted of making a list of terms or concepts that would constitute the glossary. For such a purpose, some students submitted a first proposal, and the rest of the group added, modified, or deleted the different terms until the whole group reached a consensus or agreement. A group coordinator was appointed to manage the group dynamics. The second task was to distribute the wording of the different concepts in the wiki. All of the students read what was written, and if they considered it appropriate, made modifications to the definitions of each concept, and so forth, until the glossary was finished. The last tasks were to give the appropriate format to the glossary, unify the typography used, define a common background, and incorporate images and other graphic resources. They also included the bibliography that was used at the end of the glossary (references in electronic format or links to the corresponding texts). Figures 4 and 5 show fragments of the glossary that was written by the students. 


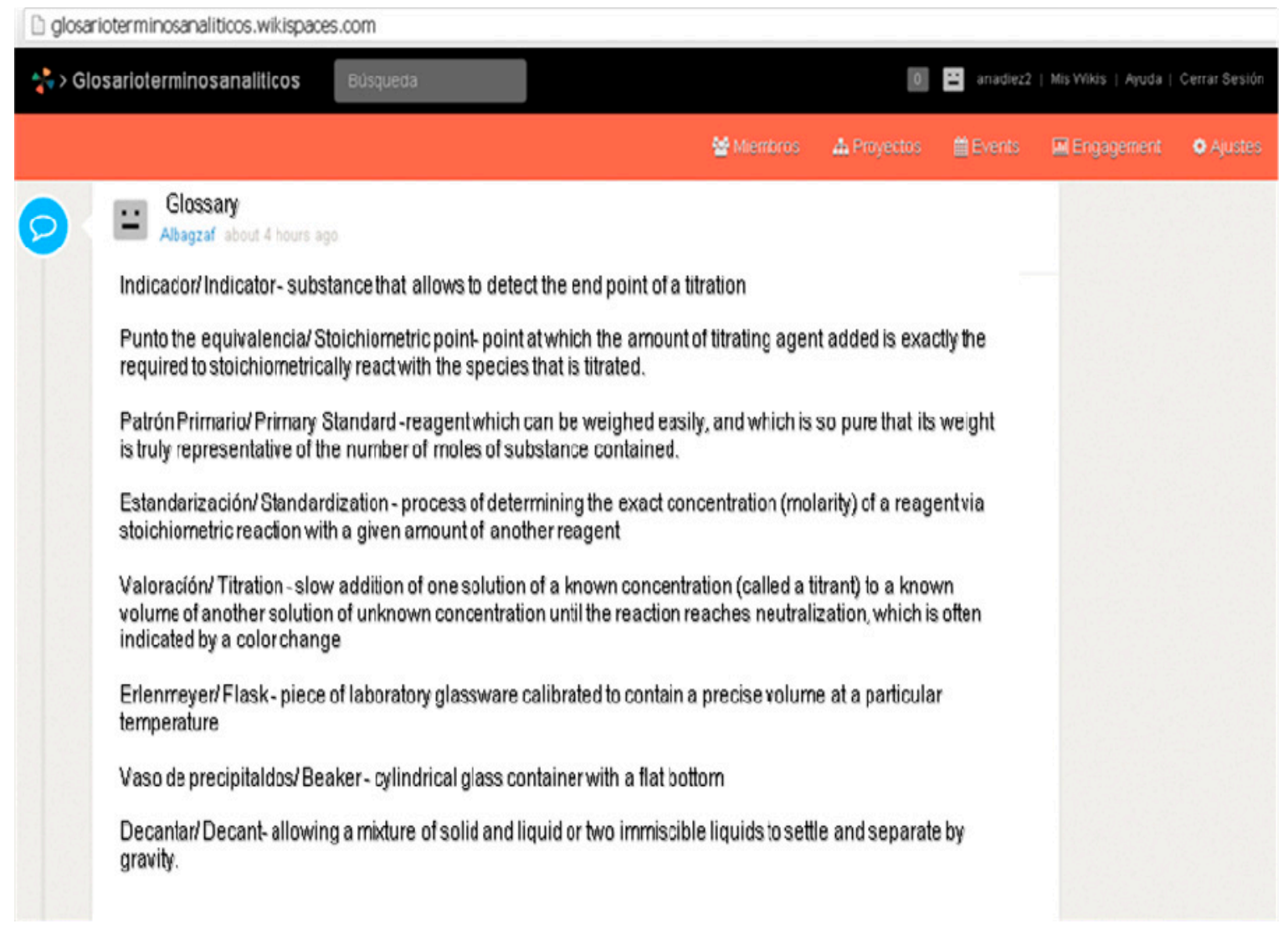

Figure 4. Fragment of the glossary written by the students in the wiki "glosarioterminosanaliticos".

Another proposed activity was to make a critical evaluation of a scientific document in the area of analytical chemistry related to the topics studied, which was posted on the wiki. Students had to read the article carefully and write a brief critical assessment of the objectives of the work, methods, results, and conclusions. They were provided with a list that included a series of questions related to the concepts that were studied during the theoretical lessons that appeared in the publication. Thus, students could identify the specific terms related to the course.

The first task carried out by each group was to read the name of the authors, look at the publication year, and interpret the title of the article. Then, they read the summary in order to understand as much as possible and identify the key argument of the document. In a quick first reading, the students marked all of the concepts and technical words that they could not understand, and discussed the doubts between them. They also made use of websites and specialized dictionaries in order to clarify those concepts. In a second reading, which was more deliberate and detained, they recognized the scientific terminology of the topic and summarized the ideas and main conclusions. Finally, they elaborated a conceptual map, grouping, connecting, and relating the different concepts, and tried to answer the formulated questions. 


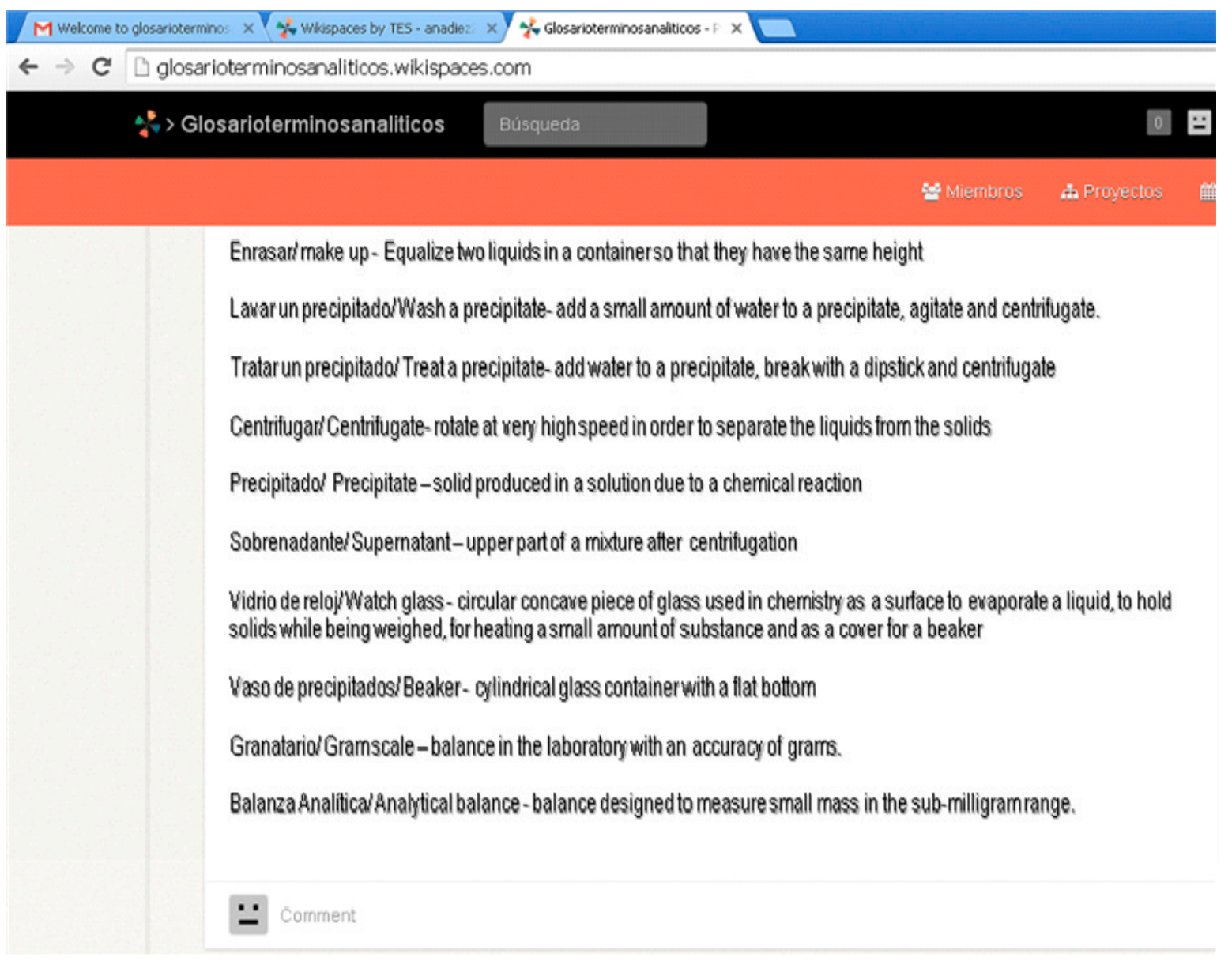

Figure 5. Fragment of the terms added to the glossary by the students.

\subsection{Degree in Telecommunication System Engineering}

The course "Digital Communications" is crucial for the students in order to understand the subjects that will be taken in subsequent courses, and that are closely related with the communications field. Moreover, this course is an asset for any engineer working in the telecommunications sector, since it provides the necessary basis to better understand present and future innovations in communication systems. The course includes 1.5 ECTS devoted to the resolution of problems directly linked to the concepts that were learned during the theoretical lessons. The teacher provides the student with a collection of model problems. However, due to a lack of time, it is not possible to solve all of them in class. In this context, a wiki can provide an adequate space for solving the problems cooperatively among students, which is always supervised by the teacher that mentors them, providing feedback and checking the veracity of the contents.

Therefore, a wiki named "ccdd-uah" was also developed within the Wikispaces environment. During the presentation of the wiki in class, the dynamics of its use, the editing and discussion mechanisms, and the basic rules of collaborative work were detailed. Figure 6 presents the home page encountered by the students after accessing the wiki through their Wikispaces account. The two pages that made up the wiki (Information Theory and Channel Coding) are shown in the right-side margin. For this first experience, the use of the wiki was restricted to the resolution of exercises, problems, and choice questions. 


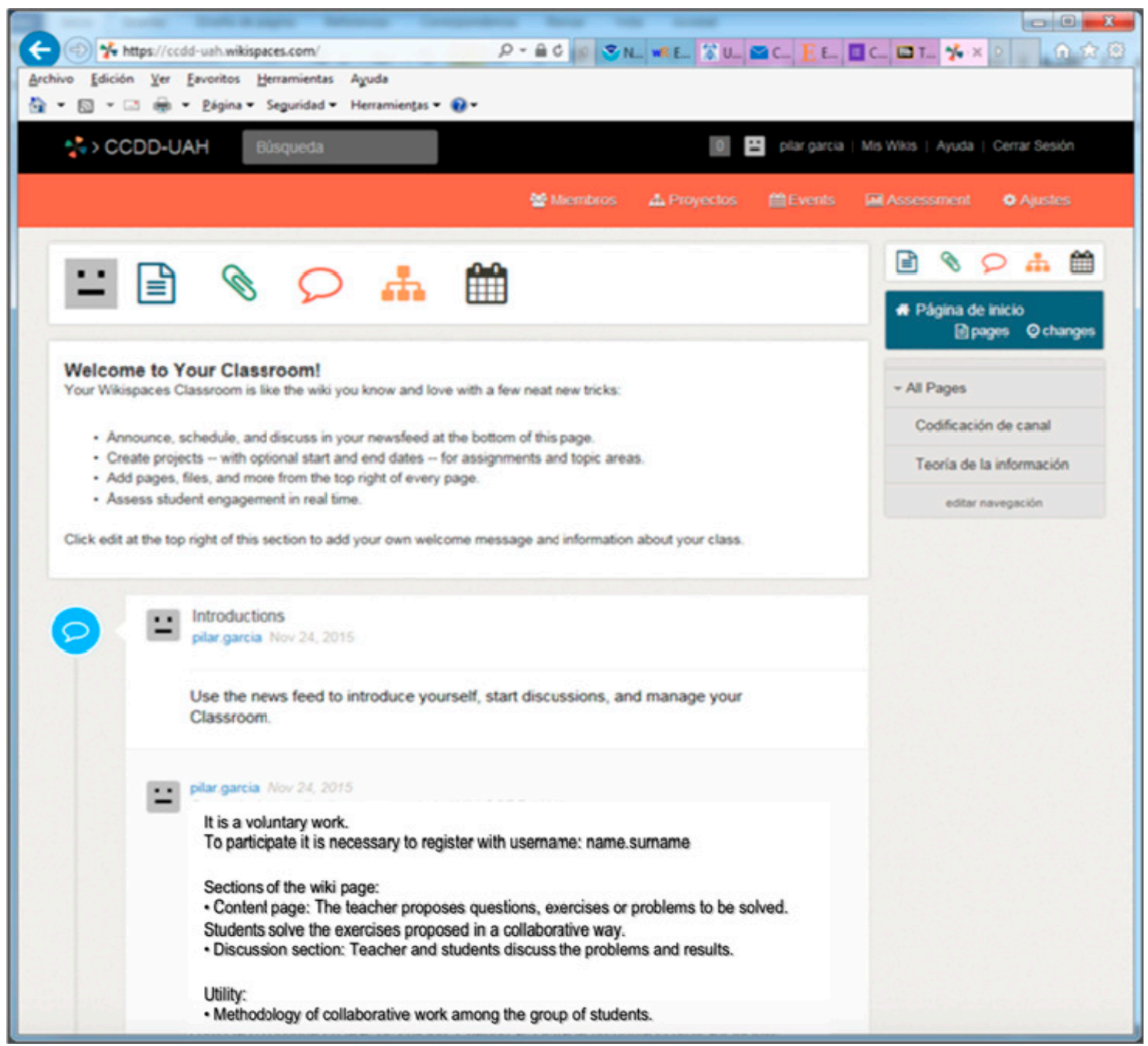

Figure 6. Initial page of the wiki "ccdd-uah".

Figure 7 shows the list of members in the wiki. The full names of the Wikispaces users have been hidden to guarantee the anonymity of the students who participated in the real activity. The two pages of the wiki were structured in the sections mentioned earlier: content or exercise area, and discussion or comment area. The former was devoted to questions, exercises, and answers. The teacher posed questions that the students answered in a collaborative way, although the teacher neither answered nor explicitly corrected the answers but commented on the answers in the discussion area. Figure 8 shows fragments of the two pages of the wiki "ccdd-uah", which contained exercises solved by the students. A peculiarity is that the teacher proposes a new question only when all of the members of the wiki accepted the answer as valid, including the teacher. In this way, the contents are constructed gradually, where the differences of one version with respect to another are located exclusively in the last exercise or inserted problem. 


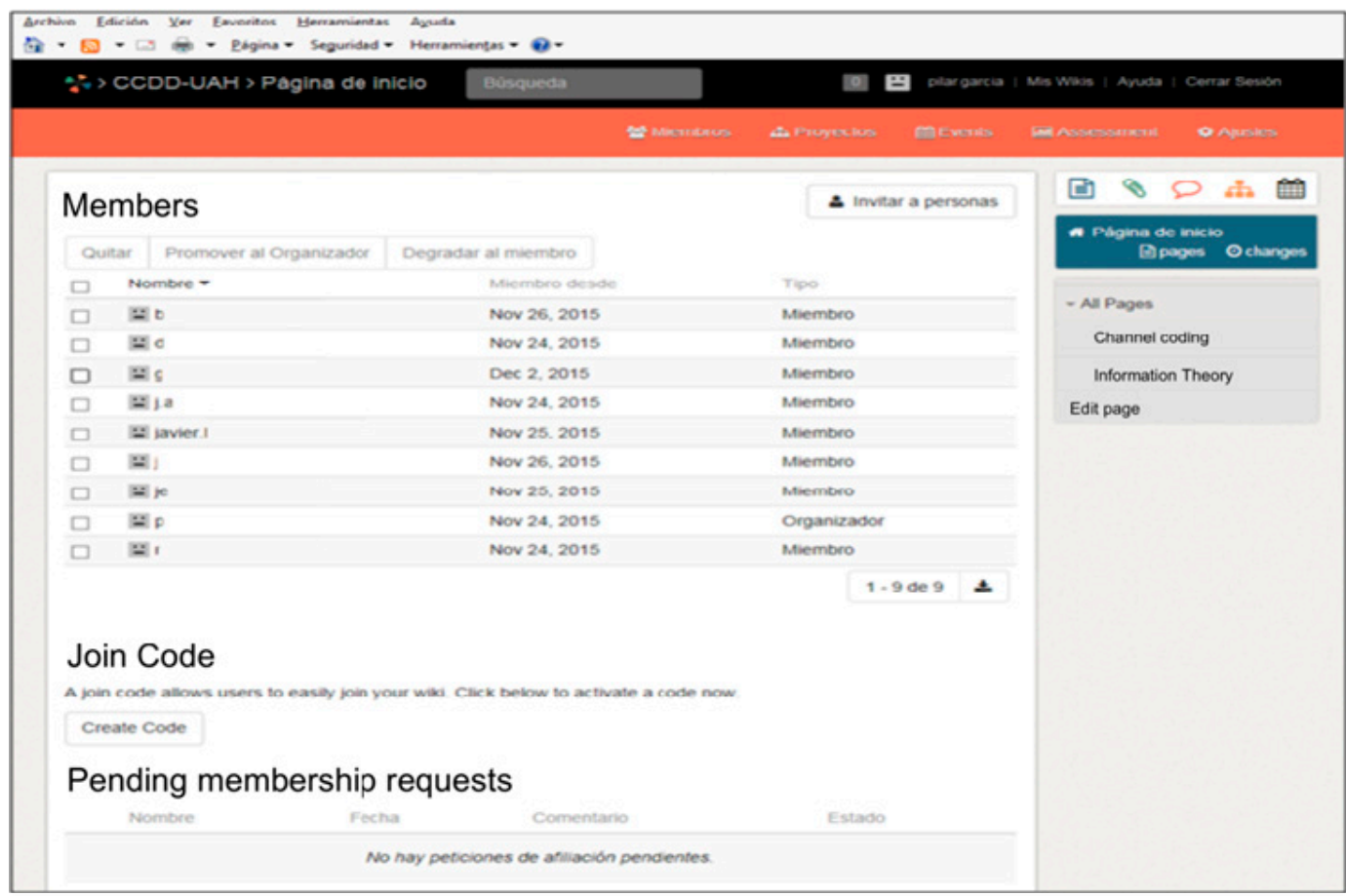

Figure 7. Initial list of members of the wiki "ccdd-uah".

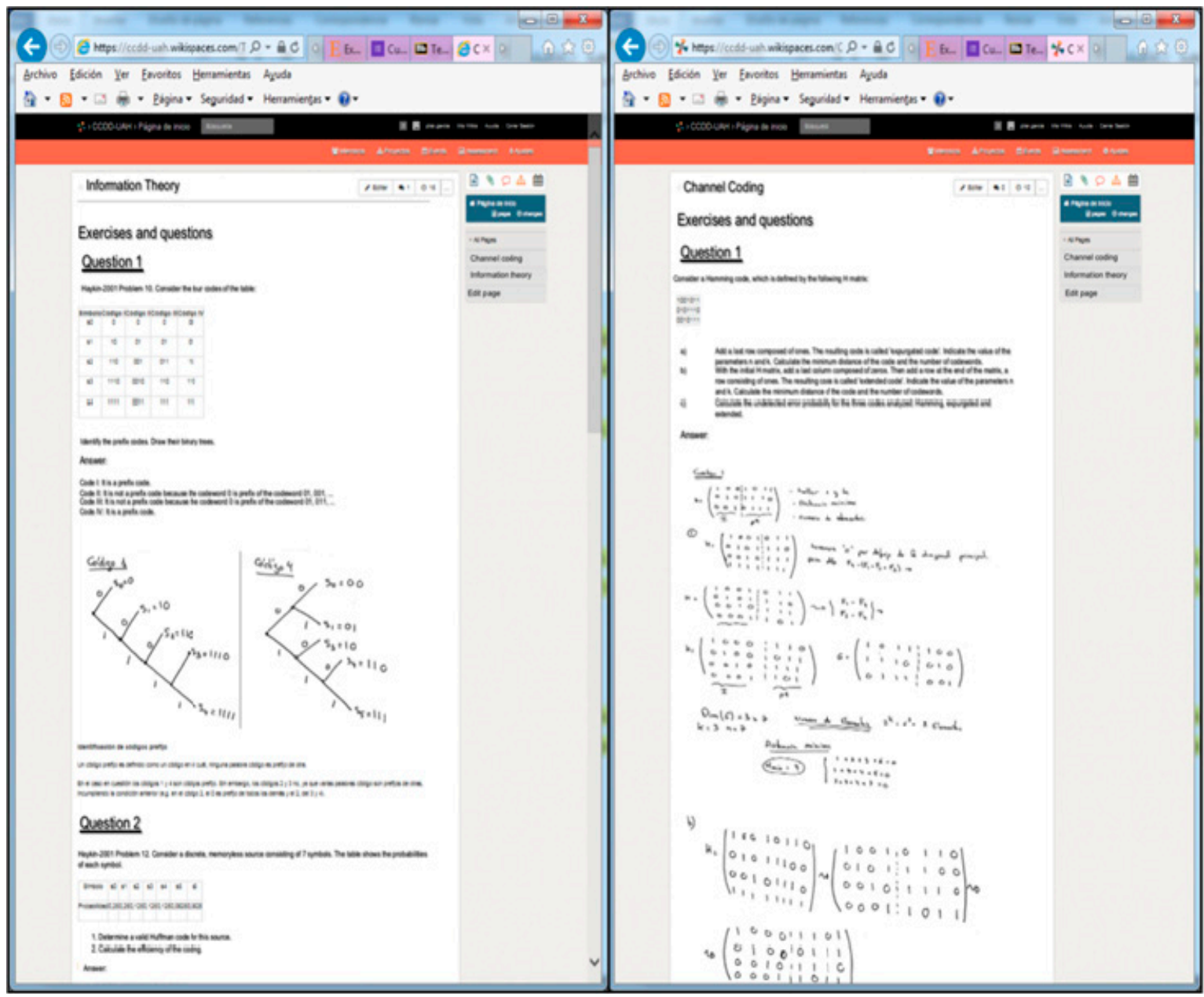

Figure 8. Examples of exercises solved by the students in the two pages that made up the "ccdd-uah" wiki. 
In the discussion area, any member could insert a comment associated with an issue or topic by opening a debate or a set of notes on the matter. It was a collective discussion area, both among students and between the students and the teacher/s. The teacher provided ideas and comments that helped redress the response to the proposed problem in the editing phase, or notified its success by adding a new exercise in the content area, resuming the process. Figure 9 includes a teacher's comment that guided the students when answering the exercises of the course.

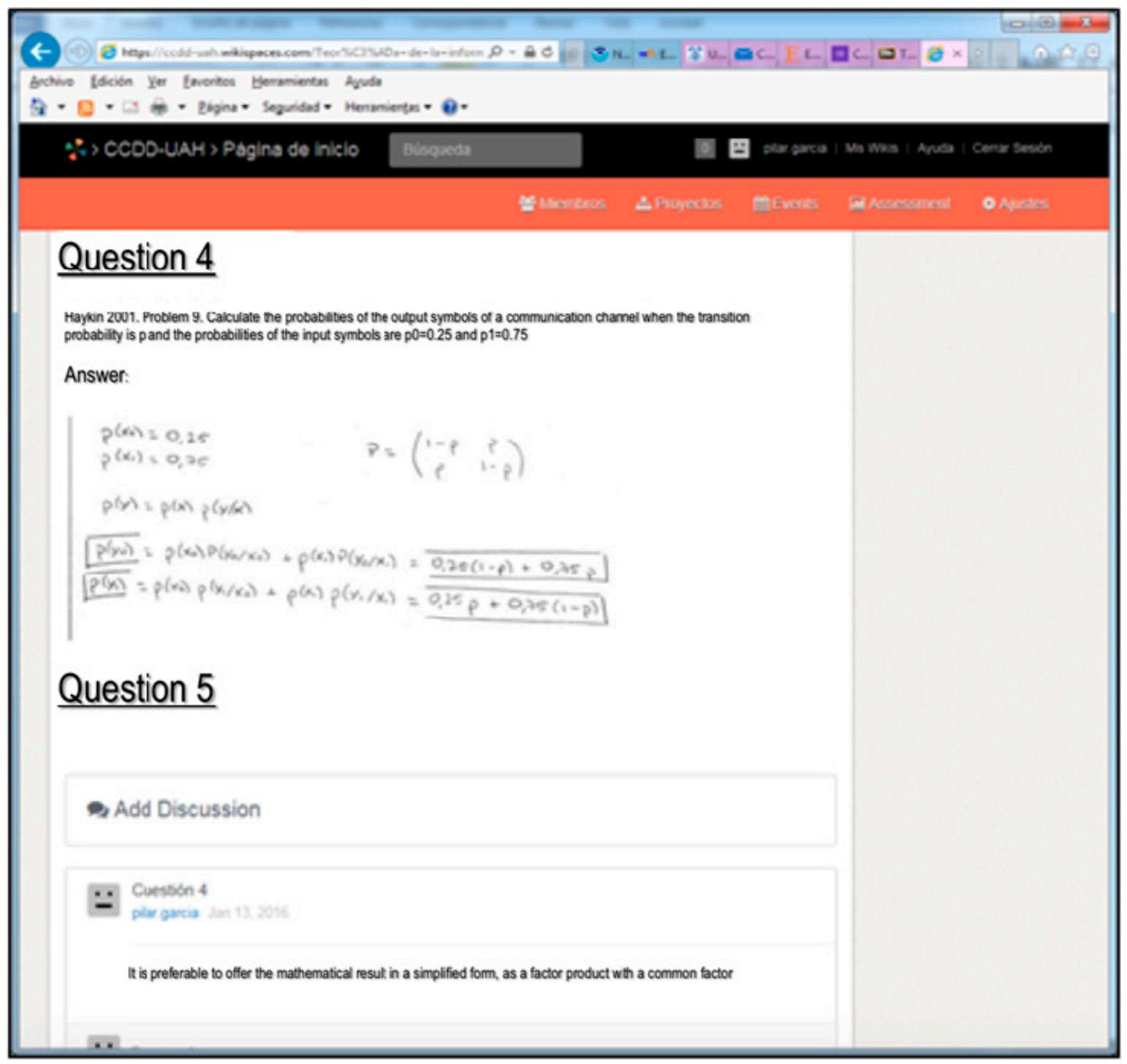

Figure 9. Example of a teacher comment suggesting a more adequate response to the proposed exercise.

\section{Results and Discussion}

\subsection{Degree in Chemistry}

Once the wiki "glosarioterminosanaliticos" was made, the first students that entered the page did not correctly understand the activity, and just incorporated terms without their definition. Then, other members started the preparation of the draft glossary, and inserted the meaning of each word in both languages as requested, arranging all of the concepts in alphabetical order. Subsequently, more students carried out a search of the literature and added new terms. Periodically, the teacher made some corrections and published the corresponding comments. The aim of the teacher's review was to examine the relevance of the terms included, ensure that the correct meaning was provided for each term, and identify the terms that were not included in the draft. The group coordinator was in charge 
of modifying the glossary according to the teacher's feedback. After formatting the text and inserting the bibliographic references, about four weeks after the wiki was set up, the final glossary was attained as the result of a collaborative effort among the students.

It is worthy to note that evaluating the collaboration and participation in a wiki presents the same problems as participation in class [21]. The assessment of student participation is highly subjective. The most common solution that is used to reduce the ambiguity associated with student participation grades is to incorporate an assessment rubric. Another effective method in evaluating student participation is the use of peer assessments [22], which is process where students rank their peers at the end of the term with a forced distribution that is designed to reduce grading leniency. However, peer assessments generally receive a negative acceptance rating from rated individuals due to perceived friendship biases. In the current study, the participation in the wiki was evaluated through the "History" section, where all of the changes that were made on the page were registered. This was a tedious task for the teacher, who had to review each individual contribution to the work and evaluate it separately. Further, during the last theoretical session of the course, the students had a day of exhibition and sharing of the work that was done in the wiki with their classmates, where they explained the work process with their successes and difficulties and the conclusions that were drawn. They were also provided with a self-assessment and co-assessment rubric (see Table 1) to assess their degree of participation in the wiki in each of the collaborative works. The students had to evaluate their peers and themselves according to the following criteria: (a) level of engagement (participation in the discussions, search for information, preparation of the work, response to teacher's feedback, etc); (b) preparedness and correctness (correct use of the specific vocabulary of the course, accuracy of the contents, search for relevant and concise information, spelling and syntactic correction, and so forth); (c) attitude (role in learning, completion of tasks, etc). An anonymous survey was also conducted so that the students were able to value the new methodology used.

Table 1. Rubric used to evaluate the collaboration and participation of the students in the wiki "glosarioterminosanaliticos".

\begin{tabular}{|c|c|c|c|c|}
\hline & Exemplary & Effective & Minimal & Unsatisfactory \\
\hline $\begin{array}{l}\text { Level of } \\
\text { Engagement }\end{array}$ & $\begin{array}{l}\text { Contributes to initiate } \\
\text { wiki discussion offering } \\
\text { insightful ideas and } \\
\text { asking meaningful } \\
\text { questions. Always } \\
\text { responds to the } \\
\text { teacher's feedback. }\end{array}$ & $\begin{array}{l}\text { Regularly makes } \\
\text { meaningful contributions } \\
\text { to wiki discussions; } \\
\text { sometimes offers ideas, } \\
\text { asks questions. Frequently } \\
\text { replies to the } \\
\text { teacher's feedback }\end{array}$ & $\begin{array}{l}\text { Contributes to } \\
\text { wiki discussion when } \\
\text { prompted. Seldom offers } \\
\text { ideas or ask questions or } \\
\text { responds to the teacher. }\end{array}$ & $\begin{array}{l}\text { Rarely makes meaningful } \\
\text { contributions to } \\
\text { wiki discussion or offers } \\
\text { ideas or asks questions. } \\
\text { Never responds to the } \\
\text { teacher's feedback. }\end{array}$ \\
\hline $\begin{array}{l}\text { Preparedness } \\
\text { and } \\
\text { Correctness }\end{array}$ & $\begin{array}{l}\text { Always uses the specific } \\
\text { vocabulary. High } \\
\text { accuracy of the contents, } \\
\text { perfect spelling and } \\
\text { syntax. Accurately } \\
\text { expresses knowledge } \\
\text { related to issues raised } \\
\text { during the discussion. }\end{array}$ & $\begin{array}{l}\text { Usually uses the precise } \\
\text { vocabulary. } \\
\text { Accuracy of the contents, } \\
\text { correctness in spelling and } \\
\text { syntax. Expresses } \\
\text { knowledge associated to } \\
\text { issues raised during } \\
\text { the discussion. }\end{array}$ & $\begin{array}{l}\text { Seldom uses the specific } \\
\text { vocabulary. } \\
\text { Low accuracy of the } \\
\text { contents. Expresses } \\
\text { limited knowledge } \\
\text { pertaining to } \\
\text { wiki discussions. }\end{array}$ & $\begin{array}{l}\text { Never makes use of the } \\
\text { specific vocabulary. } \\
\text { No accuracy of the } \\
\text { contents, incorrectness in } \\
\text { spelling and syntax. } \\
\text { Expresses no } \\
\text { relevant knowledge. }\end{array}$ \\
\hline Attitude & $\begin{array}{l}\text { Consistently exhibits a } \\
\text { positive, cooperative } \\
\text { attitude toward } \\
\text { classmates and teacher } \\
\text { during the wiki. Takes } \\
\text { an active role in own } \\
\text { learning process. Always } \\
\text { completes all the tasks. }\end{array}$ & $\begin{array}{l}\text { Generally shows a positive, } \\
\text { supportive attitude toward } \\
\text { classmates and teacher. } \\
\text { Frequently takes an active } \\
\text { role in own learning } \\
\text { process and completes } \\
\text { most of the tasks. }\end{array}$ & $\begin{array}{l}\text { Sometimes exhibits a } \\
\text { cooperative attitude } \\
\text { toward classmates and } \\
\text { the teacher. Sometimes } \\
\text { takes an active role in } \\
\text { own learning process. }\end{array}$ & $\begin{array}{l}\text { Rarely shows a positive, } \\
\text { attitude toward } \\
\text { classmates and the } \\
\text { teacher. Rarely takes an } \\
\text { active role in own } \\
\text { learning process. Never } \\
\text { completes the tasks. }\end{array}$ \\
\hline
\end{tabular}

Most of the students graded both their peers and themselves as "effective", meaning that they believed they had worked pretty well, although there were still some aspects that could be improved. In fact, the level of engagement of the wiki members was high, with several contributions per week. Also, the definitions that were used in the glossary were very accurate, with appropriate use of the specific vocabulary. However, more discussion would have been advisable, with respect to, for instance, the inclusion of more terms. In this regard, more bibliographic references should have been 
consulted, and the links should have been added to the wiki. On the other hand, the attitude of most of the students was very positive: they quickly replied to the teacher's feedback and completed all of the tasks on time.

Figure 10 summarizes the statistics of participation in the wiki. The percentage of students of "Basic Lab Operations" that passed the course was only around 33\%. As can be observed from Figure 10, the percentage of participation in the wiki was relatively low $(22.0 \%)$. All of the members of the wiki successfully passed the final exam of the course, and three of them obtained the maximum mark. Besides, $62.5 \%$ of the students that passed the exam were members of the wiki. Further, we found that the students spent between five and $12 \mathrm{~h}$ working on the activity of the wiki, depending on the degree of participation.
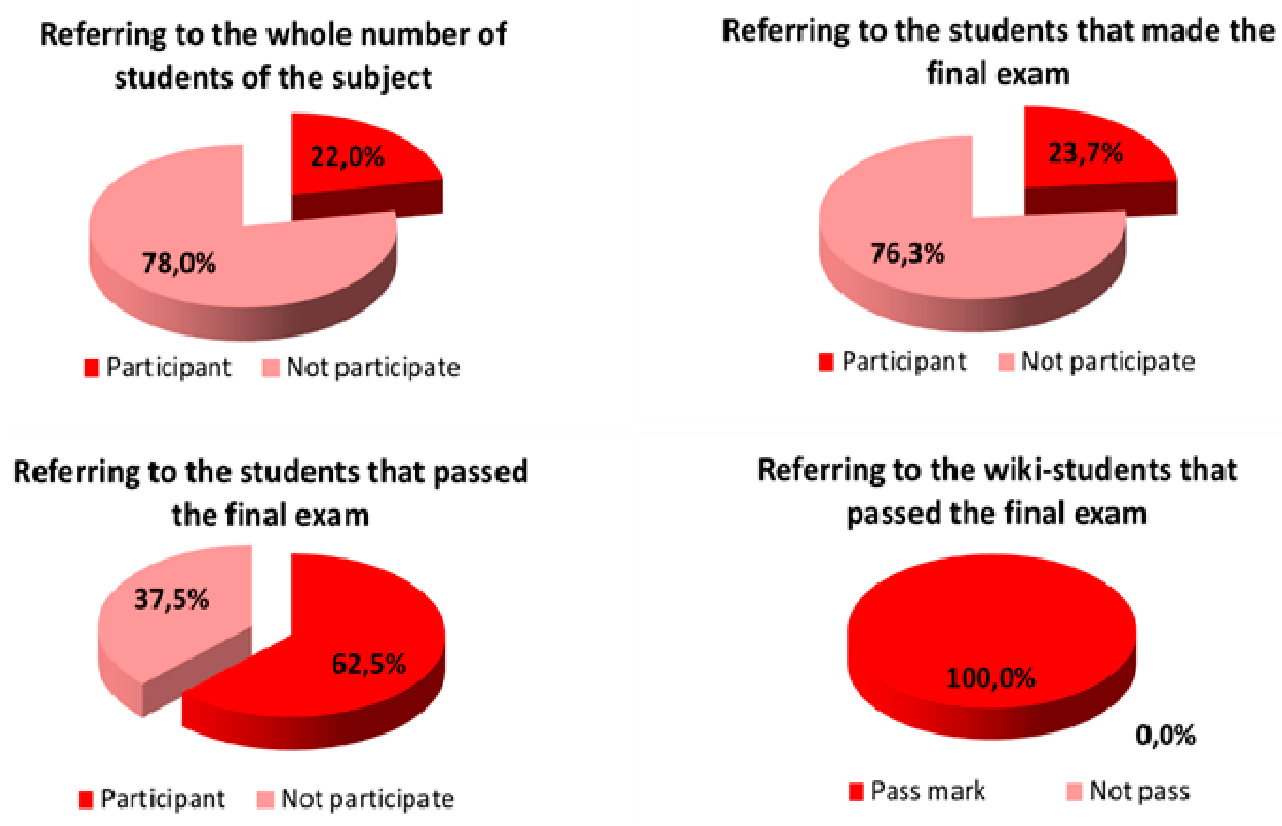

Figure 10. Statistics of participation of the students in the wiki "glosarioterminosanaliticos".

\subsection{Degree in Telecommunication System Engineering}

The participation in the "ccdd-uah" wiki was also assessed using a self-assessment and co-assessment rubric (Table 2). The students judged the work of their peers and themselves according to the subsequent criteria: (a) level of engagement (participation through offering ideas and asking questions); (b) preparation (suggestion of problems, solutions, and cooperation with the classmates); (c) behavior (correctness during the discussion and the group activities); and (d) teamwork (assist team members in finishing the exercises).

Figure 11 collects the statistics of participation in the "ccdd-uah" wiki. It can be observed that the participation in the wiki was only moderate: about $36 \%$ of the students of the whole subject or $44 \%$ of the students who did the evaluation tests. This percentage remained constant when it is referred to the students that passed the course, $43 \%$ of which corresponded to wiki users. It is noteworthy that most of the participants in the wiki $(\sim 75 \%)$ passed the course in that semester. These students are among the $53 \%$ with the best grades of the course. 
Table 2. Rubric utilized to assess the participation and work of the students in the "ccdd-uah" wiki.

\begin{tabular}{|c|c|c|c|c|}
\hline & Excellent & Good & Satisfactory & Unsatisfactory \\
\hline $\begin{array}{l}\text { Level of } \\
\text { Engagement }\end{array}$ & $\begin{array}{l}\text { Proactively and } \\
\text { systematically } \\
\text { contributes to the wiki } \\
\text { by offering ideas and } \\
\text { asking questions }\end{array}$ & $\begin{array}{l}\text { Frequently contributes to } \\
\text { the wiki by offering ideas } \\
\text { and asking questions. }\end{array}$ & $\begin{array}{l}\text { Rarely contributes to the } \\
\text { wiki by offering ideas } \\
\text { and seldom asks } \\
\text { questions. }\end{array}$ & $\begin{array}{l}\text { Rarely contributes to } \\
\text { the wiki discussion. }\end{array}$ \\
\hline Preparation & $\begin{array}{l}\text { Always prepared with } \\
\text { the assignments. } \\
\text { Actively seeks and } \\
\text { suggests solutions to } \\
\text { problems. }\end{array}$ & $\begin{array}{l}\text { Usually prepared with the } \\
\text { assignments. Improves in } \\
\text { solutions suggested by } \\
\text { other groups members. }\end{array}$ & $\begin{array}{l}\text { Rarely prepared with the } \\
\text { assignments. Does not } \\
\text { suggest problem } \\
\text { solutions, but it is } \\
\text { willing to try solutions } \\
\text { suggested by other } \\
\text { members. }\end{array}$ & $\begin{array}{l}\text { Almost never prepared } \\
\text { with the assignments. } \\
\text { Does not try to solve } \\
\text { problems or help } \\
\text { others solve problems. }\end{array}$ \\
\hline Behavior & $\begin{array}{l}\text { Never displays } \\
\text { disruptive behavior } \\
\text { during discussions. }\end{array}$ & $\begin{array}{l}\text { Rarely displays disruptive } \\
\text { behavior } \\
\text { during discussions or } \\
\text { group activities. }\end{array}$ & $\begin{array}{l}\text { Occasionally displays } \\
\text { disruptive behavior } \\
\text { during discussions or } \\
\text { group activities. }\end{array}$ & $\begin{array}{l}\text { Frequently displays } \\
\text { disruptive behavior } \\
\text { during discussions. }\end{array}$ \\
\hline Teamwork & $\begin{array}{l}\text { Works to complete all } \\
\text { group goals. Always has } \\
\text { a positive attitude } \\
\text { toward the tasks of } \\
\text { others. Assists team } \\
\text { members in finishing the } \\
\text { exercises. }\end{array}$ & $\begin{array}{l}\text { Usually helps to complete } \\
\text { group goals. Usually has a } \\
\text { positive attitude toward } \\
\text { the tasks of others. } \\
\text { Sometimes assists team } \\
\text { members. }\end{array}$ & $\begin{array}{l}\text { Occasionally helps to } \\
\text { complete group goals. } \\
\text { Sometimes makes fun of } \\
\text { the group tasks or the } \\
\text { works of others. Does } \\
\text { not assist team members. }\end{array}$ & $\begin{array}{l}\text { Does not work well } \\
\text { with others and shows } \\
\text { no interest in } \\
\text { completing the group } \\
\text { goals. Often makes fun } \\
\text { of the work of others. }\end{array}$ \\
\hline
\end{tabular}

\section{Referring to the whole number of students of the subject}

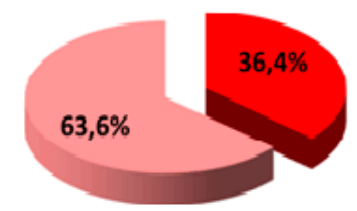

- Participant $=$ Not participate

Referring to the students that passed the final exam

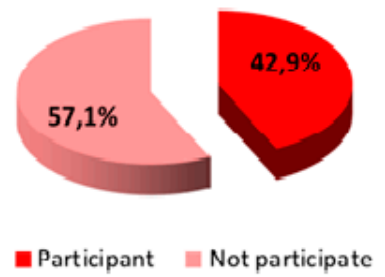

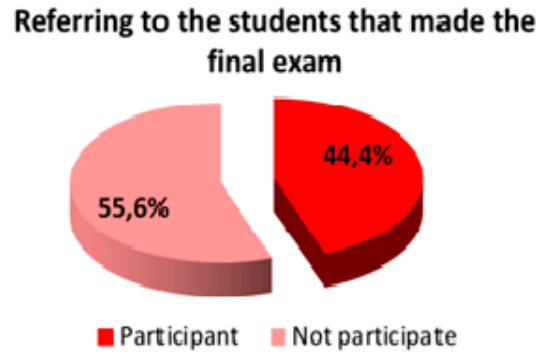

Referring to the wiki-students that passsed the final exam

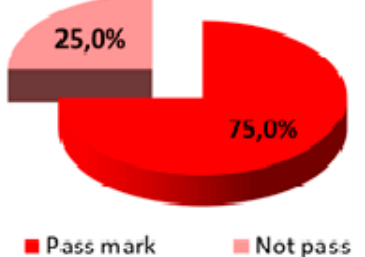

Figure 11. Statistics of participation of the students in the wiki "ccdd-uah".

Open-ended questionnaires were provided in a final seminar at the end of the course to explore the reasons for modest participation in the wiki, and a chart collecting the statistics of the results obtained is shown in Figure 12. Multiple causes were exposed by the students, including technical issues such as the absence of useful guidelines, lack of time due to overlapping with work deadlines from other modules, low self-esteem such as doubts about the quality of their contributions, lack of self-confidence to write in the online tool or edit/correct what other students wrote, concern that the activity was not taken into account in the qualification of the subject, the belief that wiki technology is focused on leisure and is not expected in an educational context, that writing content in the online tool is the teacher's job, rather than the students', and a general lack of interest. 


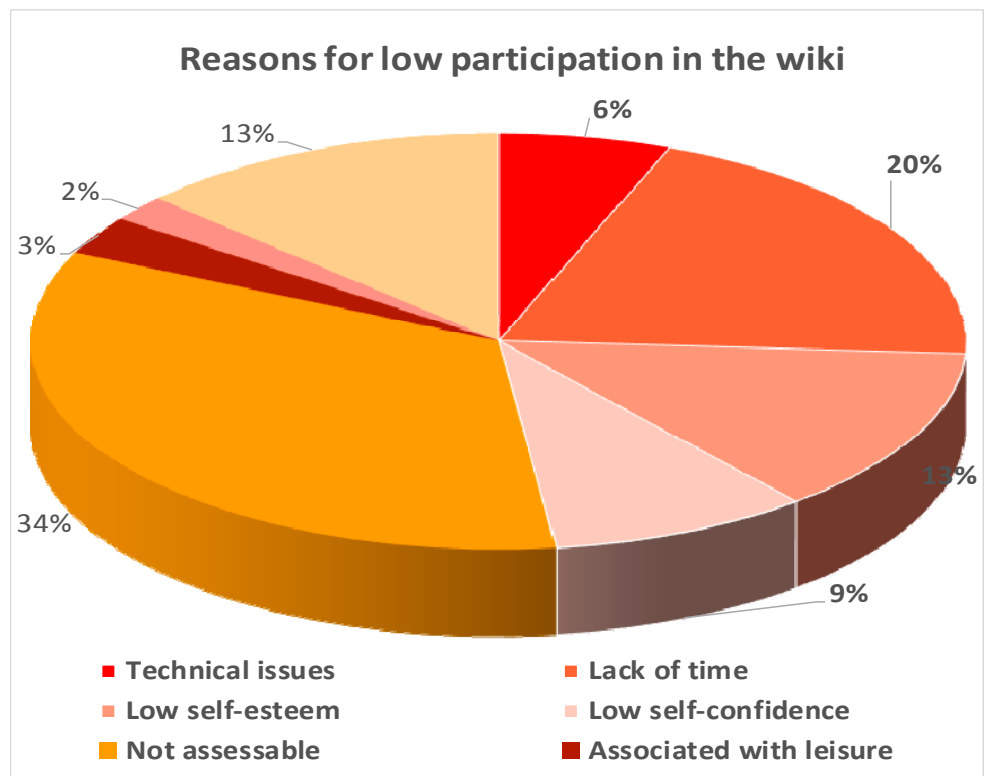

Figure 12. Statistics of the different reasons given by the students for the low participation in the the wiki "ccdd-uah".

\section{Comparison of the Response to the Use of Wikis in the Degrees of Chemistry and Telecommunication System Engineering}

For both degrees, four different patterns could be distinguished among the students according to their level of participation in the wiki, which were in agreement with the qualifications indicated in the assessment rubrics:

- $\quad$ Type 1: Students who successfully passed the course, due to bringing the material up to date and tapping all of its potential, with an individual contribution to the final wiki text greater than $10 \%$;

- Type 2: Students focused on the study of the course contents with an individual contribution that ranged between $5 \%-10 \%$ of the whole text;

- Type 3: Students who worked just enough to pass the subject, and whose individual contribution ranged between $2 \%-5 \%$;

- Type 4: Students who essentially ignore the existence of the social software resource, and their individual contribution did not exceed the $2 \%$ of the wiki work.

According to the educational learning theories detailed in Section 2, the four aforementioned student patterns (Types 1-4) could be associated with the collaborative, constructivist, cognitivist, and behaviorist learners, respectively.

Figure 13 (right) compares the percentage of students corresponding to each of the above-indicated patterns for both degrees.

In the case of Chemistry, the highest percentage $(\approx 45 \%)$ corresponded to the most dedicated students (Type 1), while the least interested (Type 4) only represented $9 \%$ of the total number of participants in the wiki. Types 2 and 3 had intermediate contributions that stood for $27 \%$ and $18 \%$, respectively. Regarding the degree in Telecommunication System, fewer students were involved in the wiki compared to the degree in Chemistry, since the Type 1 pattern accounted only for the $12 \%$ of the Telecommunication System students, while most of them (44\%) belonged to Type 4, and showed very low dedication in the study of the subject of Digital Communications. In fact, some of them were mere observers or readers, and did not edit any text on the wiki. This conditions the percentage of text contribution by pattern, as will be discussed below. Types 2 and 3 also presented intermediate values of $19 \%$ and $25 \%$, respectively. 


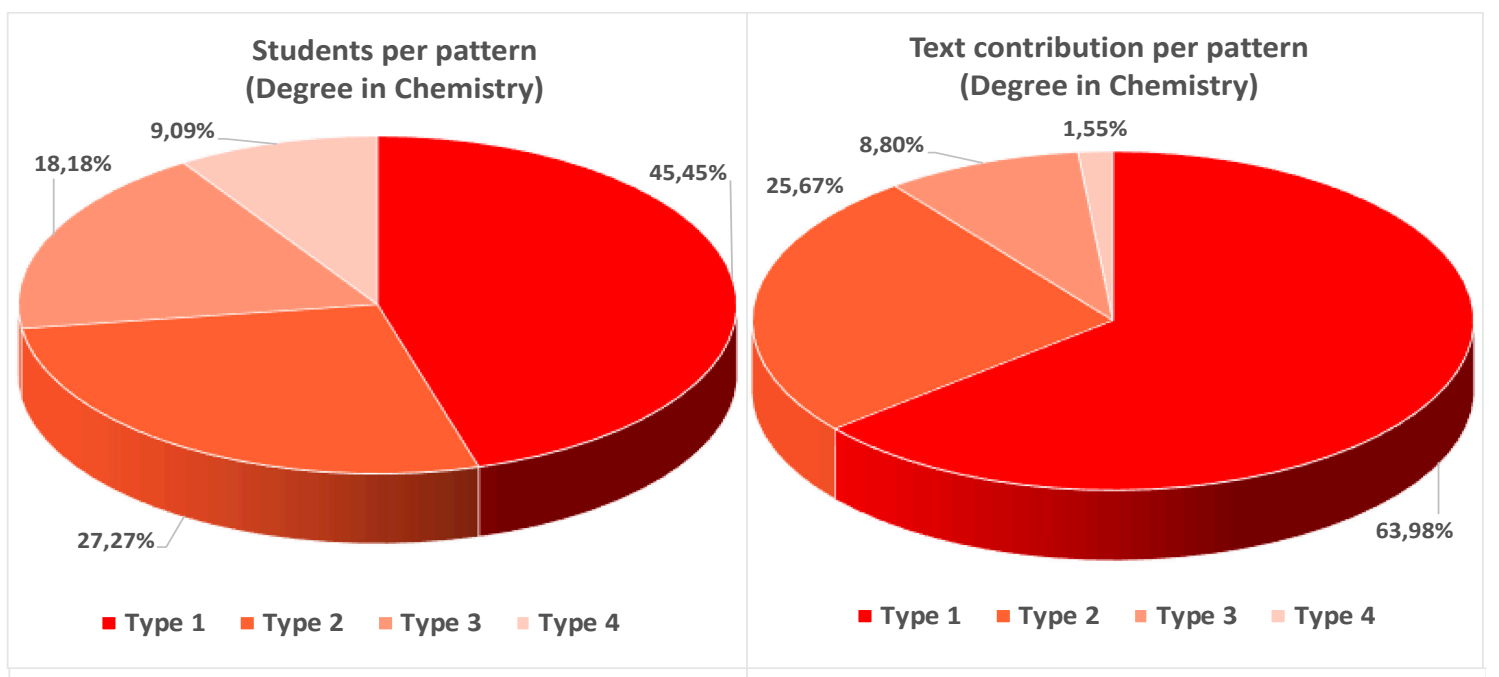

Students per pattern

(Degree in Telecom. System Engineering)

Text contribution per pattern

(Degree in Telecom. System Engineering)
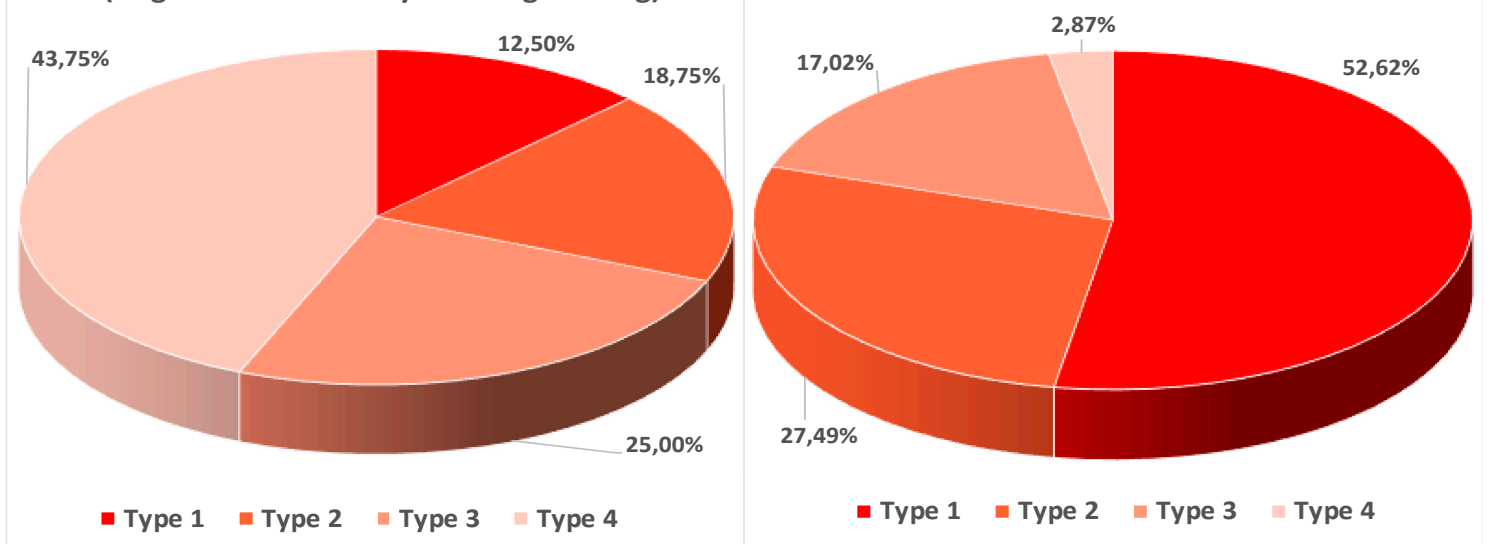

Figure 13. Statistics of percentage of students corresponding to each pattern and text contribution per type of pattern (see explanation in the text) for the wikis developed in the degree in Chemistry and Telecommunication System Engineering.

The percentage of text contribution to the wiki corresponding to each of the above-mentioned patterns for both degrees is also compared in Figure 13 (right). As expected, in the degree of Chemistry, the Type I pattern showed the highest contribution to the wiki glossary (about $64 \%$ of the work), while the Type 4 contributed less than $2 \%$. The other two patterns had contributions of $26 \%$ (Type 2 ) and $9 \%$ (Type 3). These results are consistent with the pattern definitions that were indicated above. It is worthy to note that almost half of the wiki participants in the degree in Chemistry met this pattern of highly dedicated student. Surprisingly, in the degree of Telecommunication System Engineering, the Type 1 provided the majority of the work done (53\%) despite it being the smallest group, with only $12 \%$ of the participants. Conversely, the largest group of participants (Type 4) accounted for only $3 \%$ of the wiki contents, and the other two patterns showed intermediate contributions. Again, the results are in agreement with the pattern descriptions made above, since Type 1 made the greatest contribution.

On the other hand, if the wiki activities had a compulsory character, the percentage of student participation would increase. Nonetheless, this would not significantly change the contribution tendency, that is, the absolute values would likely rise, while the relative ones would remain essentially unaffected.

Figure 14 compares the number of visits of the wikis "glosarioterminosanaliticos" and "ccdd-uah" as a function of time during the first semester. 

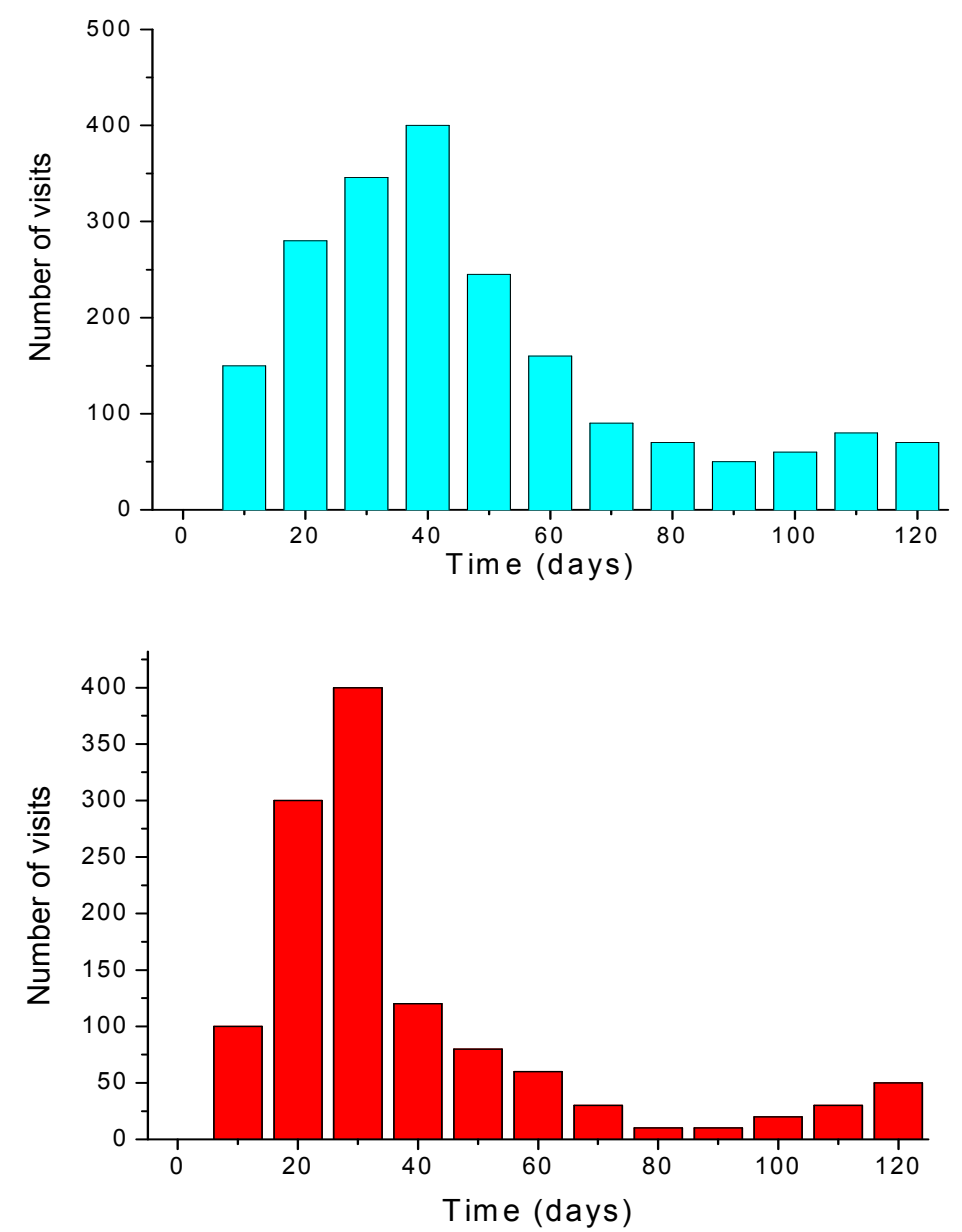

Figure 14. Number of visits to "glosarioterminosanaliticos" (top) and "ccdd-uah" (bottom) wikis as a function of time during the first semester.

Clearly, the number of visits was systematically higher for the degree in Chemistry, which was in agreement with their higher level of participation, as discussed above. In both cases, the participation of the students in the wiki was neither constant nor gradual: initially, the wiki experienced a lot of visits and modifications, which rose during the first month, but then moved on to a long period of lower activity (in the degree of Chemistry) or even inactivity (in the degree of Telecommunication System Engineering), which was coincident with the peaks of work of the students, particularly during the exam period. Only at the end of the course of Telecommunication System Engineering was there again a certain level of participation, since the students had more free time and desired to finish all of the tasks on time. Therefore, more effort should be focused on maintaining the level of student engagement. Efforts at fostering student motivation can be slow to affect behavior and can require special and lengthy preparation. Students are individuals, so a variety of approaches may be needed in order to motivate different students. It will be helpful to previously know the interest of each of them in order to connect these interests with the course contents. However, this is a tedious task, particularly in courses involving large groups of students.

\section{Conclusions and Future Perspectives}

Noticeably, most of the students that participated in the wikis passed the courses. Further, since the activities were optional, only the students who were more committed to the courses were involved in the wikis. Therefore, it seems that the combination of students' dedication to the course and wiki participation resulted in students' course success. This could be related to the wiki also serving as a 
study guide: a trustworthy source of information that helped the students prepare for exams. Further, some of the exercises and problems that were solved in the wikis were similar to exam questions.

On the whole, it could be concluded that the use of wikis in courses in the fields of sciences and engineering provided a number of educational benefits:

- Progressive knowledge building and problem solving;

- Synopsis, discussion, critical logic, and reflection capacities;

- Increased student engagement and interest in the course contents;

- Combination of both collaborative and self-regulated learning;

- Active and more effective student-teacher communication;

- Appropriate use of emerging social networking technologies;

- Information and knowledge exchange among students.

In our point of view, it is not appropriate to apply a rating system on the activities of the wikis, at least not for all of the students. Although the interface of the application offers a history of the editions that were performed, identifying the user names, date, and time for each of the pages independently, it lacked a similar recording option for reading accessed by its members. On the other hand, taking into account the collaborative nature of the social software, it is likely that some of the students worked in groups on the wiki outside the classroom, editing the contents via a single user, despite all of them contributing simultaneously, and this aspect is impossible to register. Thus, one of the objectives of the developed activities is to offer the students greater self-control over their learning. The voluntary character of the activities promoted an enhanced management of the learning process by the students, who could focus their efforts on their writing assignment rather than on the assessment. Further, another purpose of the developed methodology was to instill in the students a certain degree of autonomy for their learning, facilitating guidelines so that they could correct themselves throughout the different activities.

Overall, the results obtained in the degree in Chemistry were better than those attained in the degree in Telecommunication System Engineering. The differences observed could arise from the fact that the students of each Degree have their own characteristic behavior and performance in the classroom, as well as their own way of working the subject content. Thus, a teacher who educates students from different degrees, located in different buildings, can clearly check the particularities of each group in the classroom environment. For example, Chemistry students sit in groups, which are usually composed of friends, with each student carrying his personal computer, and even some of them facing away from the blackboard. There is a positive relationship among the students in the class, which results in a higher level of wiki participation, since the students are more motivated to share their personal material with those for whom they feel affection. On the contrary, Engineering students are sparsely placed within the classroom, dispersed in seats spread out from each other, and seem much more individualized than in the faculty of Chemistry. Therefore, it seems that the modest participation in the wiki of the "Digital Communications" course was also related to the lower connection that existed among the students.

The differences that were found could also be rationalized considering that the subjects who were investigated belonged to different years of the degrees. Thus, the students of the first year of Chemistry had to elaborate a glossary of terms, which was similar to the tasks that they were used to doing during secondary school. In contrast, the students of the third year of Telecommunication System Engineering were asked to solve more complex exercises and problems. These students are in general more independent and self-organized; as a result, it was more difficult to lead them to a methodical task with a continuous dedication. Further, they usually attend simultaneously to courses corresponding to different years, or combine their studies with part-time or even full-time jobs; hence, their availability is significantly reduced compared to first-year students, who are typically fully devoted to the study.

On the other hand, the moderately low level of participation in the wikis, particularly for the degree in Telecommunication System Engineering, could be related to the shortage of time 
of the students and the lack of flexibility of the activities. Continuous assessment meant that the activities proposed in the different courses overlap, and become concurrent during the most intense periods. In general, students do not have enough time for dedication to all of the courses they attend simultaneously. Unfortunately, this leads to the work times on a particular course being distributed in bursts, instead of being distributed continuously (as dictated by basic study techniques). Consequently, the wikis followed a non-gradual development: during the first month, the number of edits and visits increased suddenly, and then moved on to a long period of less activity (in the degree of Chemistry) or even lethargy (in the degree of Telecommunication System Engineering), which was most notable at the beginning of the exam period. In order to avoid severe periods of inactivity in the applications, flexible criteria as well as consensual planning and deadlines for working with the wikis should be set up in concordance with the students.

Due to the simultaneity of numerous editors, the format of the content in the wiki was typically inhomogeneous. An initial agreement of the authors in the establishment of a basic format for the content of the wiki is highly desirable. This can define the type and size of the source, the insertion of figures and attachments, bibliographic references, etc. Further, specialized roles or functions among the students could also be established, which should always be flexible. Examples of these could be the searcher of the bibliography, creator of indexed labels, spelling checker, or organizer of the general structure. Further, it would be beneficial to explore the function of notifying all of the users of the changes performed in the wiki. As a result, the activity of some of the users in the wiki could boost the activity of the rest of the members. This is manifested in social networks, where a comment can bring an avalanche of interventions.

Further, this study demonstrates the significance of managing students' expectations in regard to activities that do not count toward the final grade. It is not feasible to implement a wiki into a course with conventionally designed content and expect the students to instantaneously participate. Conversely, the course content should be redesigned around the wiki itself. By proposing the use of social software for tasks of greater scope and complexity than the resolution of exercises, a higher level of student participation and increased use of this methodology would be achieved. Further, the tasks would have a compulsory character. They could be similar to the group activities that were proposed during the course, although the form of delivery would be the online platform instead of the conventional delivery to the teacher.

The design of multiple activities is also encouraged; hence, the students would be able to choose those that they considered more interesting to boost their learning. Among them, we could find the following. (1) Writing on a hot topic connected to the course; hence, the students could apply their knowledge and the specific concepts and terms learned during the course. It would consist of collaborative writing; consequently, the students would have to organize themselves, correcting and modifying what the other students wrote. They would also choose the topic to develop; hence, they would have to carry out a literature search on the subject. (2) Respond to particular questions related to the themes of the course. This activity would require the use of the specific terms and capacity of making a summary in order to answer the specific questions. Some of them would be numerical problems. The students would answer in a collaborative way, and the teacher would not directly correct the answers, but rather comment on them in the discussion area. Such modifications would enable the progress of educational learning toward formats that incorporate the collaborative capabilities of the Internet.

Author Contributions: Conceptualization, methodology and resources, A.M.D.-P. and P.G.-D.; Formal Analysis and Data curation R.P.-C.; Writing-Original Draft Preparation, A.M.D.-P.; Writing-Review \& Editing, A.M.D.-P. and P.G.-D.

Funding: This research received no external funding.

Conflicts of Interest: The authors declare no conflict of interest. 


\section{References}

1. Leuf, B.; Cunningham, W. The Wiki Way: Quick Collaboration on the Web; Addison-Wesley Longman Publishing: Boston, MA, USA, 2001; ISBN 0-201-71499-X.

2. Mifflin, H. The American Heritage Dictionary of the English Language, 4th ed.; American Heritage Publishing Company: Boston, MA, USA, 2000; ISBN 0640206348348. [CrossRef]

3. Mattison, D. Quickiwiki, Swiki, Twiki, Zwiki and the Plone wars: Wiki as a PIM and collaborative content tool. Searcher 2003, 11, 32-48.

4. Rost, A. The concept of hypertext in digital journalism. In Proceedings of the 23th Conference and General Assembly IAMCR/AIECS/AIER, Barcelona, Spain, 21-26 July 2002.

5. Cole, M. Using Wiki technology to support student engagement: Lessons from the trenches. Comput. Educ. 2009, 52, 141-146. [CrossRef]

6. Ross-Hellauer, T. What is open peer review? A systematic review. F1000Research 2017, 6, 588. [CrossRef] [PubMed]

7. Zheng, B.; Niiya, M.; Warschauer, M. Wikis and collaborative learning in higher education. Technol. Pedagog. Educ. 2015, 24, 357-374. [CrossRef]

8. Karasavvidis, I. Wiki uses in higher education: Exploring barriers to successful implementation. Interact. Lear. Environ. 2010, 18, 219-231. [CrossRef]

9. Keller, M.M.; Neuman, K.; Fischer, J.E. The impact of physics teachers' pedagogical content knowledge and motivation on students' achievement and interest. JRST 2017, 54, 586-614. [CrossRef]

10. Williams, J.B.; Jacobs, J.S. Exploring the use of blogs as learning spaces in the higher education sector. Australas. J. Educ. Technol. 2004, 20, 232-247. [CrossRef]

11. Wenger, E. Supporting Communities of Practice: A Survey of Community-Oriented Technologies. 2001. Available online: http:/ / www.ewenger.com/tech (accessed on 1 September 2018).

12. Parker, K.; Chao, J. Wiki as a Teaching Tool. IJKLO 2007, 3, 57-72. [CrossRef]

13. Schunk, D.H. Learning Theories: An Educational Perspective, 6th ed.; Pearson: Raleigh, NC, USA, 2012.

14. Yilmaz, K. The Cognitive Perspective on Learning: Its Theoretical Underpinnings and Implications for Classroom Practices. Clear. House 2011, 84, 204-212. [CrossRef]

15. Lin, B.; Hsieh, C. Web-based teaching and learner control: A research view. Comput. Educ. 2001, 37, 377-386. [CrossRef]

16. Alavi, M. Computer-mediated collaborative learning: An empirical investigation. MISQ 1994, 18, 159-174. [CrossRef]

17. Smith, M.K. Action Research. The Encyclopaedia of Informal Education. 2007. Available online: http:/ / www. infed.org/research/b-actres.htm (accessed on 28 November 2018).

18. Webb, G. Becoming Critical of Action Research for Development; New Directions in Action Research; Zuber-Skerritt, O., Ed.; Falmer Press: London, UK, 1996.

19. Apotheker, J.; Veenstra, I. Twenty-first Century Skills: Using the web in Chemistry Education. In Chemistry Education: Best Practices, Opportunities and Trends; García-Martínez, J., Serrano-Torregrosa, E., Eds.; Wiley: Berlin, Germany, 2015; pp. 563-594. [CrossRef]

20. Valcarcel, M. Principles of Analytical Chemistry; Springer: Berlin, Germany, 2000.

21. Czekanski, K.E.; Wolf, Z.R. Encouraging and evaluating class participation. JUTLP 2013, 10, 7.

22. Melvin, K.B. Rating Class Participation: The Prof/Peer Method. Tech. Psychol. 1988, 15, 137-139. [CrossRef]

(c) 2018 by the authors. Licensee MDPI, Basel, Switzerland. This article is an open access article distributed under the terms and conditions of the Creative Commons Attribution (CC BY) license (http://creativecommons.org/licenses/by/4.0/). 